\title{
Influence of conspecific stress odors and shock controllability on conditioned defensive burying
}

\author{
JON L. WILLIAMS \\ Kenyon College, Gambier, Ohio
}

\begin{abstract}
In Experiment 1, rats received a session of 80 inescapable tail shocks or no shocks while restrained in a tube. During tests of conditioned defensive burying $24 \mathrm{~h}$ later, the bedding of the chamber contained odors from either stressed or nonstressed conspecific donor rats. Following a single prod shock, subjects that had had prior shocks or that were tested with the stress odors spent significantly less time burying the prod, made smaller piles of bedding, and displayed more freezing behavior. The combination of prior shock and stress odors during later testing enhanced these effects. In Experiment 2, a yoked group of rats that was given inescapable shocks, in contrast to a group that had wheel-turn escape training and one that was restrained but not shocked, later showed significantly less burying and more freezing when tested for defensive burying with stress odors present. In both experiments the duration of burying and the heights of piles were positively correlated, and both of these measures were negatively correlated with freezing. The demonstrated capacity of unconditioned stress odors to mediate different degrees of fear, depending upon the controllability of prior shock, is related to other studies of learned helplessness, and the predominance of freezing over burying is discussed in terms of various types of defensive strategies, stimulus-control processes, and the author's stress-coping-fear-defense (SCFD) theory.
\end{abstract}

The debilitating behavioral and physiological consequences of uncontrollable stress have been the focus of much research and theoretical interest. In rats and mice, inescapable shock has been found to interfere with subsequent escape learning (e.g., Anisman, Suissa, \& Sklar, 1980), appetitive instrumental learning (e.g., Rosellini, 1978 ), and various unlearned behaviors, such as general activity (e.g., Drugan \& Maier, 1982), exploration (e.g., Bruto \& Anisman, 1983), and maternal responses (Williams, 1984). Furthermore, inescapable shock has been shown to alter a variety of neurotransmitters (e.g., Weiss et al., 1981) and to produce both opioid and nonopioid pain analgesia (e.g., Maier et al., 1983). These disruptions in behavior and physiology have frequently been referred to as "learned helplessness effects," because they do not follow exposure to equivalent amounts of escapable shock and thus are a product of the uncontrollability of the stressor.

Of particular relevance to the present set of experiments are findings that indicate that inescapable, as opposed to escapable, shock has pronounced effects on various types of species-typical agonistic behaviors. Williams (1982) demonstrated that dominant male colony rats given inescapable shock showed virtually no aggression or offensive behavior and an increase in defensive responding

This research was supported by USPHS Research Gran 1RD3MH38528-01. The author wishes to thank Richard Lincoln for the construction of the apparatus and the initial pilot research on this topic, and Charles Rice and Mary Finkbeiner for their helpful comments. Reprint requests should be addressed to Jon L. Williams, Department of Psychology, Kenyon College, Gambier, OH 43022. when tested later with naive conspecific intruders. In contrast, this abrupt shift in the occurrence of offensive and defensive behaviors was not observed in dominant colony residents that had been previously exposed to wheel-turn escapable shock. More recently, Williams and Lierle (1986, Experiment 2), using a similar combination of escape-yoked shock and later resident-intruder testing, reported that rats receiving inescapable shock displayed an enhanced series of defensive responses (e.g., freezing, rearing, lying on the back) when tested as intruders in colonies known to have aggressive male residents. A subsequent experiment (Williams \& Lierle, 1986, Experiment 3) further demonstrated the importance of the psychological dimension of stress controllability by showing that this potentiation of intruder defense could be prevented or reversed by having a session of escapable shock occur before or after, respectively, the inescapableshock session. We interpreted these changes in speciestypical responses as support for my stress-coping-feardefense (SCFD) theory. Briefly, this theory assumes that exposure to escapable shock, as opposed to inescapable shock, produces less overall fear conditioning of contextual cues (e.g., stress odors, the experimenter). Presumably, this difference in contextual fear conditioning is the result of the "safety-signal" properties of the feedback inherent in performing the escape response (Mineka, Cook, \& Miller, 1984; Overmier, Murison, Skoglund, \& Ursin, 1985). The differential levels of fear for subjects receiving escapable versus yoked-inescapable shock are also presumed to influence their subsequent agonistic behavior because of the inadvertent presence of a num- 
ber of transituational conditioned stimuli (e.g., stress odors) during testing (Minor \& LoLordo, 1984). Finally, on the basis of my previous research and that of others (e.g., D. C. Blanchard \& R. J. Blanchard, 1984; Fanselow \& Baackes, 1982), I postulate in this theory that the presence of conditioned stress cues during testing results in the animal's performing a variety of defensive behaviors, to the exclusion of other responses.

In order to further test the major assumptions of the SCFD theory, in the present experiments I examined the possible influence of inescapable shock, conspecific stress odors, and shock controllability on another type of defensive behavior-conditioned defensive burying. Pinel and his colleagues (Pinel \& Treit, 1978, 1979, 1981; Terlecki, Pinel, \& Treit, 1979) reported that when suitable bedding material is available, rats bury a localized source of aversive stimulation, such as a wall prod from which they have received a single electric shock. These studies also established that the temporal and spatial contiguity between the prod and the shock results in the prod's becoming a feareliciting stimulus. Subsequent testing with the prod in a chamber to which the subject has been habituated has been shown to activate a reliable sequence of defensive responses: initial freezing in locations away from the prod, followed by a series of approach-withdrawal movements and, finally, the partial or complete burying of the prod (see Pinel \& Wilkie, 1983, for a review of this literature).

The defensive-burying paradigm seemed ideal for examining the possible unconditioned, as well as conditioned, fear reactions elicited by conspecific stress odors alone or in combination with previous exposure to escapable or inescapable shock. Would inescapable shock and/or the presence of conspecific urine and feces odors from stressed donors in the test bedding facilitate or suppress the defensive burying of a prod that was the source of a single shock? I speculated that because the burying of the prod represents an active form of avoidance behavior, the sustained performance of this response would be disrupted by the defensive behavior of freezing for animals experiencing intense fear. Previous studies have reported that fear, elicited by novel stimulation (Oberdieck \& Cheney, 1982) or the presence of a cat (Fanselow $\&$ Lester, in press), produces freezing and interferes with the manipulation of bedding material. The present experiments should provide a sensitive technique for examining the relationship between freezing and burying by having stress odors present in the actual bedding. Under these conditions, the putative defensive response of burying requires that the animal manipulate the feared stimulus with its forepaws for an extensive period if it is to cover the prod. This procedure should also be interesting in terms of studying the conflict between the fear of a localized source (i.e., the shock prod) and the fear of very salient unconditioned stress odors, which might also produce varying degrees of conditioned fear, depending on the organism's specific stress history (i.e., escapable shock, inescapable shock, or no shock). More specifically, Experiment 1 was designed to examine the possible effects of preshock, stress odors, and their interaction on defensive burying and freezing, whereas Experiment 2 focused on whether the controllability versus uncontrollability of stress influenced these defensive responses.

\section{EXPERIMENT 1}

Rats innately recognize certain stimuli and react to them with defensive behavior. Such stimuli include cats (e.g., R. J. Blanchard, Fukunaga, \& D. C. Blanchard, 1976), human experimenters (R. J. Blanchard, Flannelly, \& D. C. Blanchard, 1986), and dominant conspecifics (e.g., Williams, 1982). Even without the infliction of pain or tactile contact, rats spend a significant portion of their time freezing when confined in the vicinity of these threatening stimuli. Likewise, stress odors released by conspecifics are important behavioral controlling stimuli during encounters with predators or conspecifics (Brown, 1979). For some time it has been known that rats can discriminate the odors of stressed conspecifics from those of nonstressed conspecifics (Valenta \& Rigby, 1968). The presence of these stress odors has been shown to interfere with the acquisition of one-way shock avoidance learning (Dua \& Dobson, 1974). One objective of the present experiment was to determine whether the presence of conspecific stress odors would enhance freezing and interfere with conditioned defensive burying following prod shock. Therefore, one group of rats had conspecific stress odors present in their bedding and another group was exposed to familiar odors of nonstressed conspecifics during tests of burying and freezing.

The SCFD theory and the findings of Minor and LoLordo (1984) suggest that conspecific stress odors present at the time of inescapable shock mediate a variety of previously described learned helplessness effects by enhancing defensive behavior (e.g., freezing) and suppressing the performance of other learned responses and species-typical patterns of behavior. Therefore, a second objective of this experiment was to directly test this critical assumption by giving half of the subjects in the stressodor and nonstress-odor groups a series of inescapable shocks, and the other half no shocks, $24 \mathrm{~h}$ prior to the test of prod burying. More specifically, the initial stress session involved preshocking groups of rats simultaneously in plastic restraining tubes, while the nonshocked controls were restrained in similar tubes located in a separate room. I hypothesized that the preshocked subjects would later show less defensive burying and more freezing, particularly when conspecific stress odors were present in the bedding.

\section{Method}

Subjects. Thirty-two male albino rats of Holtzman descent, weighing $370-450 \mathrm{~g}$ at the time of testing, served as subjects. They were maintained on a 12:12-h reverse light:dark cycle and had food and water continuously available in their individual home cages. They were tested during the dark phase.

Apparatus. Inescapable shocks and restraint conditions were administered to the preshocked groups of subjects in a Plexiglas tube 
$28 \mathrm{~cm}$ in length and $7 \mathrm{~cm}$ in diameter. The rat's tail was taped to a thin Plexiglas rod that extended from the rear of the tube. Shocks were delivered from a Lafayette 82400 shock source through two electrodes attached to the rat's tail. All shock presentations were electronically controlled. The shock tubes and the nonshock restraining tubes were located in separate rooms, so that the unshocked rats were not exposed to the stress odors produced by the shocked rats; white noise (75 dB SPL) was presented in both rooms.

Conspecific stress-odor material was obtained from rat donors shocked in a BRS/LVE shuttlebox, which was $45 \times 20 \times 20 \mathrm{~cm}$ with the metal divider removed. This shuttlebox was housed in a soundattenuating chamber in which a 75-dB SPL noise was presented. On the floor of the shuttlebox, beneath the grids, ground corncob mash served as bedding to absorb feces and urine odors. Inescapable scrambled grid shocks were delivered from a Lafayette 82400 shock source, which was electronically controlled. The shuttlebox was located in the same experimental room as the previously described preshock tubes.

The test chamber for defensive burying consisted of a metal colony cage, $36 \times 36 \times 41 \mathrm{~cm}$; the opening was on the top, which was completely covered by a piece of Plexiglas. On one side of the test chamber, a wooden dowel $13 \mathrm{~mm}$ in diameter, wrapped with two uninsulated wires, protruded $6.5 \mathrm{~cm}$ into the test chamber. This prod was mounted $2 \mathrm{~cm}$ above a $6.5-\mathrm{cm}$ layer of commercial bedding material made of ground corncobs. Shock presentations through this prod were controlled manually, and were delivered from a Lafayette 82400 shock source. The bedding material was sifted to remove any long stringy pieces that might interfere with burying behavior or pile measurements. The chamber was placed inside a larger sound-attenuating chamber, which was illuminated by a 4-W $120-v$ incandescent light bulb centered above the test chamber. The outer chamber was ventilated by a small fan, and white noise ( $85 \mathrm{~dB} \mathrm{SPL}$ ) was presented by means of a speaker located on the ceiling. The rats were observed through a small window covered with red film, which was in the ceiling of the outer chamber. There was a large light difference between the test chamber and the outside room area, which remained dark. This experimental room was separated from the preshock and restraining tube areas by a $30-\mathrm{m}$ hallway.

Procedure. All rats were handled and habituated to the test chamber according to the following procedure. On Day 1 , they were habituated to the chamber in groups of 4; on Days 2 and 3, they were habituated in pairs; and on Day 4, they were habituated individually. All habituation periods were $30 \mathrm{~min}$. On Day 5 , the rats were assigned randomly to one of two conditions ( $n s=16$ ): preshock (PS) or nonshock (NS). PS rats were individually restrained, in groups of 4 , in the tubes and given $801-\mathrm{mA}, 5-\sec$ inescapable shocks presented on a random-time schedule with a mean intershock interval of $60 \mathrm{sec}$ and a range of 30-120 sec. The NS subjects were restrained for $90 \mathrm{~min}$ in separate tubes located in another room, but they received no shocks.

On the following day, 5 odor-donor rats of the same strain, sex, and age as the experimental animals were individually given $51-\mathrm{mA}$, 5 -sec inescapable shocks presented according to the previously described random-time schedule. The bedding material beneath the grid floor of the shuttlebox, which contained the feces and urine of the donors, was collected. For half of the rats in the PS and NS groups, the soiled bedding from stressed conspecifics was distributed evenly over the surface of the familiar bedding in the defensiveburying test chamber. For the remaining subjects, bedding from the home cage trays (i.e., odors from nonstressed conspecifics) was spread evenly over the familiar bedding of the test chamber. Thus, a factorial design consisting of the following four groups was created: preshocked and later tested with stress odors (PS/SO), preshocked and tested with no stress odors (PS/NSO), nonshocked and tested with stress odors (NS/SO), and nonshocked and tested with no stress odors (NS/NSO). The order in which the SO and NSO subjects were tested for burying was counterbalanced.
At the start of the test session, the rat was placed in the center of the experimental chamber, facing the prod, and the Plexiglas lid and door to the outside chamber were secured. When the rat placed both of its forepaws on the prod, a 120-V ac, 6.5-mA shock was initiated by the experimenter; the shock was terminated by the subject's withdrawal. The rat's behavioral reaction to the shock was scored according to the 5-point scale devised by Gray, Terlecki, Treit, and Pinel (1981). The categories from 0-4, respectively, are no discernible reaction, startle but no immediate withdrawal, startle and withdrawal to the far end of the chamber, jumping followed by rapid withdrawal, and a reflexive leap to the far end of the chamber.

The shock signaled the initiation of the 20 -min test session during which the durations of freezing and of burying behaviors were recorded. Freezing behavior was scored when the rat showed an immobilized, crouched posture. Burying behavior was scored when the rat was oriented toward the prod and sprayed bedding material at it with rapid pushing of the forepaws. As has been the practice (Pinel \& Treit, 1978), the duration-of-burying score for each subject was simply the cumulative duration of these bursts of directed spraying. A cumulative freezing score was calculated for each rat in a similar manner. The responses of the rats during prod-shock conditioning and later testing were recorded by an experienced observer by means of a chart recorder. Previous videotaped observation sessions had been conducted to ascertain that interreliability of scoring exceeded .95 . At the end of each test session, the height of the highest pile of bedding material within $5 \mathrm{~cm}$ of the prod was measured. Then the chamber was thoroughly cleaned with an industrial vacuum and all surfaces were washed with a $5 \%$ solution of ammonium hydroxide.

\section{Results and Discussion}

The duration-of-burying and height-of-piles scores for the four groups are presented in Figure 1. As both of these measures show, prior shock exposure as well as the presence of conspecific stress odors suppressed defensive burying. Furthermore, this suppression was considerably enhanced in the PS/SO condition.

A two-way analysis of variance on the duration of burying data confirmed that preshocked rats buried less than did nonshocked rats $[F(1,28)=37.43, p<.001]$, and that stress odors also reduced burying behavior $[F(1,28)$ $=66.05, p<.001]$. The shock $\times$ stress odor interaction was not found to be significant. A Newman-Keuls post hoc test indicated that both of the preshocked groups (Groups PS/NSO and PS/SO) differed significantly $(p<.01)$ from their respective nonshocked groups (Groups .NS/NSO and NS/SO). A separate analysis of variance indicated a similar pattern with regard to the height-of-piles data. Exposure to preshock $[F(1,28)=$ $26.11, p<.001]$ and stress odors $[F(1,28)=53.33$, $p<.001]$ reduced the height of piles, and the interaction of the two factors was not significant. A NewmanKeuls test revealed that Group PS/NSO differed from Group NS/NSO at the .05 level, and Group PS/SO differed from the remaining groups at the .01 level. Finally, within-group Spearman correlations for duration of burying versus height of the piles showed that these measures were positively correlated for Group NS/NSO $[r(6)=.79, p<.01]$, Group PS/NSO $[r(6)=.85$, $p<.01]$, Group NS/SO $[r=.49, p<.08]$, and Group PS/SO $[r(6)=.84, p<.01]$. 

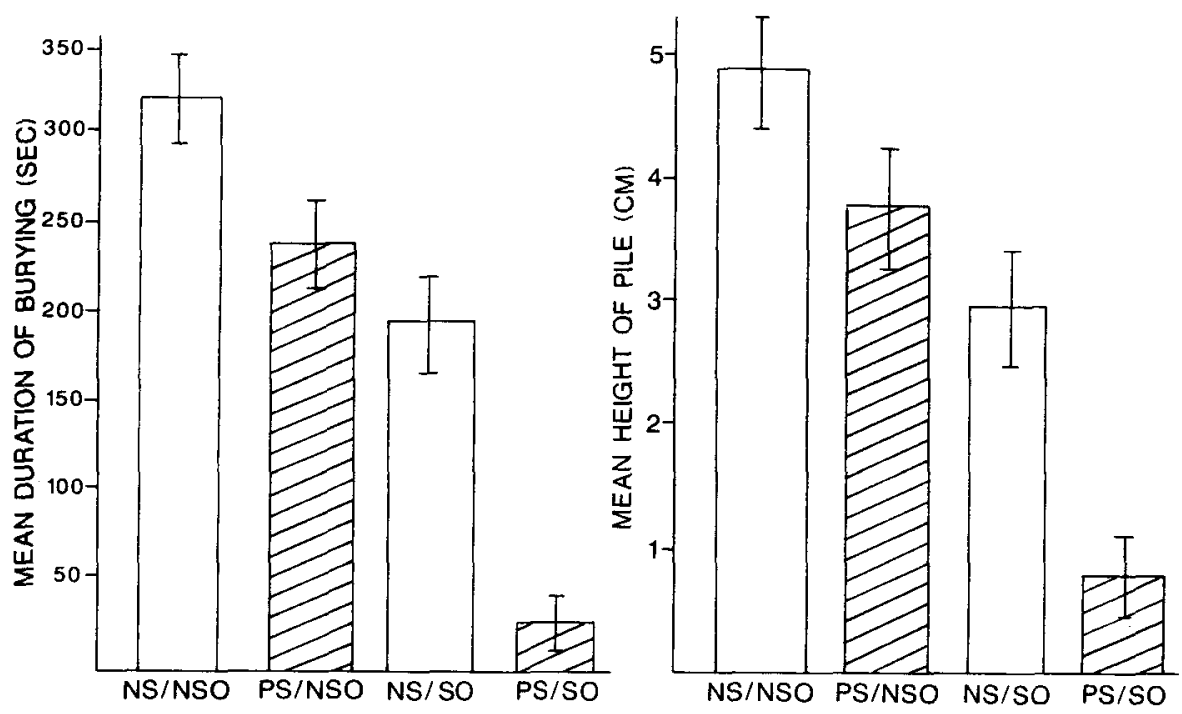

Figure 1. Mean duration of burying (in seconds) of a shock prod (left panel) and mean height (in centimeters) of piles of bedding material (right panel) for subjects given preshock (PS) or no shock (NS) 24 h prior to a session of conditioned defensive burying with conspecific stress odors (SO) or no stress odors (NSO) present in the bedding material.

Figure 2 illustrates the duration of freezing behavior observed in each of the four conditions. These findings show effects opposite those previously described for burying duration and height of piles. A two-way analysis of variance indicated that enhanced freezing was displayed by preshocked rats $[F(1,28)=60.61, p<.001]$ and rats tested with stress odors $[F(1,28)=50.01, p<.001]$. The interaction between these two main effects was also found to be significant $[F(1,28)=9.27, p<.01]$. A Newman-Keuls post hoc test established that Group PS/NSO showed more freezing than did Group NS/NSO at the .01 level. Group PS/SO was also found to differ significantly from all of the other groups at the .001 level. Thus, a powerful synergistic effect was seen in terms of freezing when rats were given shocks 1 day before they were exposed to stress odors in their test environment. Within-group Spearman correlations for the duration-offreezing scores versus the defensive-burying and heightof-piles scores were all significantly negative at the .05 level or less, with $r s(6)$ ranging from -.65 to -.97 .

The cited differences in defensive burying, heights of the piles produced, and freezing behavior do not appear to be the result of any systematic differences among the groups in terms of their unconditioned reactions to the prod shock. A two-way analysis of variance of the observational ratings made of the rats' reactions to the shock failed to disclose statistically significant effects.

These findings illustrate the robustness of the conditioned defensive burying phenomena (e.g., Pinel \& Treit, 1978) for rats that were not exposed to stress stimuli. By means of this paradigm, it was also revealed that conspecific stress odors from shocked donor animals were capable of producing freezing and disrupting burying behavior. These results provide support for the notion that freezing is a very prevalent response during tests of defensive burying (Moser \& Tait, 1983). The fact that conspecific odors from stressed, as opposed to nonstressed, rats produce freezing is consistent with the previously reported findings that rats can make such a discrimination (Valenta \& Rigby, 1968) and that stress odors can interfere with the performance of learned responses (Dua \& Dobson, 1974).

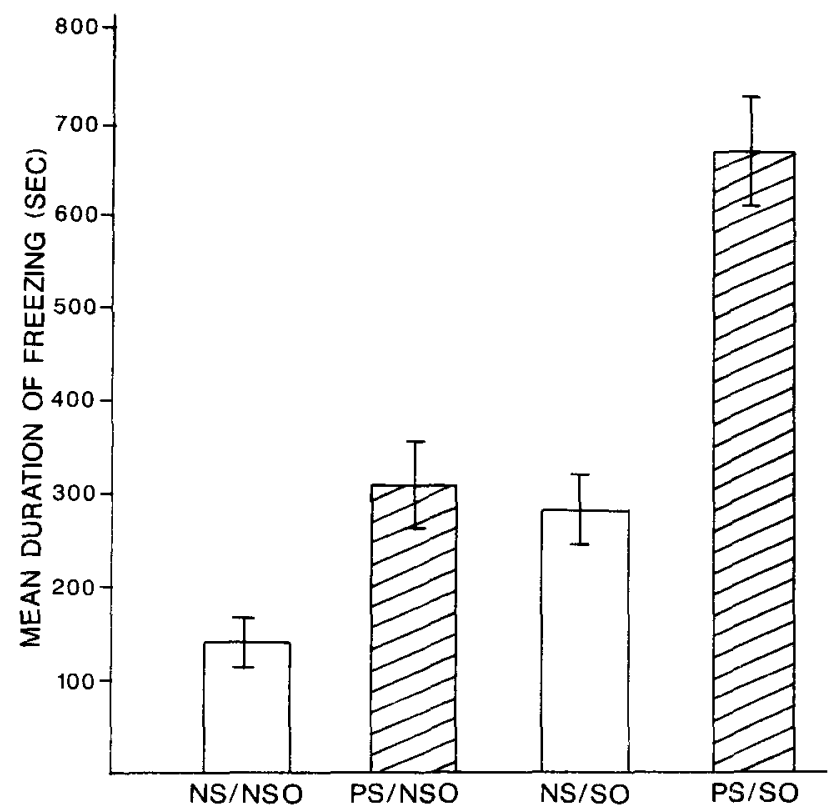

Figure 2. Mean duration of freezing (in seconds) by subjects given preshock (PS) or no shock (NS) $24 \mathrm{~h}$ prior to a session of conditioned defensive burying with conspecific stress odors (SO) or no stress odors (NSO) present in the bedding material. 
Exposure to shock was found to decrease defensive burying and increase freezing when subjects were later tested in the presence or absence of stress odors. The effects of preshock in the absence of stress odors may have occurred because of a number of transituational unconditioned stimuli, such as the presentation of electric shock or experimenter handling cues. However, the potentiation of the alterations in freezing and burying by the combination of shock and stress odors is thought to be the result of the classical conditioning of these contextual odors. Thus, the odors from stressed conspecifics for the preshocked rats (i.e., Group PS/SO) may have elicited an unconditioned as well as a conditioned fear reaction during testing. Finally, Minor and LoLordo (1984) have previously shown that odors associated with shock are very effective mediators of fear in subsequent tests conducted in a different environment.

\section{EXPERIMENT 2}

Experiment 1 demonstrated that stress from a prior shock session potentiated defensive freezing and interfered with defensive burying, particularly when rats were exposed to conspecific stress odors during testing $24 \mathrm{~h}$ later. The previously cited learned helplessness research and the SCFD theory suggest that the psychological dimension of controllability is a major factor in determining the effects of stress. Thus, controllable, or escapable, aversive events, as opposed to uncontrollable ones, have little or no consequence. Particularly relevant to the present study are my earlier findings that inescapable shock, in contrast to escapable and nonshocked treatment, resulted in increments in defense in dominant colony males (Williams, 1982) and in isolated colony intruders (Williams \& Lierle, 1986) during subsequent resident-intruder testing.

The purpose of Experiment 2 was to investigate whether shock controllability would influence burying and freezing behaviors during later tests of conditioned defensive burying with conspecific stress odors present in the bedding material. The procedure used was the well-known triadic design, in which the rats in one group were given escape training in a wheel-turn box, and the rats in the second group were yoked to escape partners so that the two groups received exactly the same number and duration of shocks. The rats in the third group were restrained in the wheel box but were not given shock. Each of the rats in the three groups was tested $24 \mathrm{~h}$ later, using the prod-shock procedure described in Experiment 1 for Groups NS/SO and PS/SO.

\section{Method}

Subjects. Twenty-four male albino rats of Holtzman descent, raised at Kenyon College and weighing 410-452 g, served as subjects. All maintenance and laboratory conditions in this experiment were the same as those for Experiment 1.

Apparatus. Shock and restraint conditions were administered in three identical Plexiglas wheel-turn boxes measuring $15.5 \times 12.0 \times 17 \mathrm{~cm}$. A 64-cm-diam grooved Plexiglas wheel was located on the front wall and extended $1.5 \mathrm{~cm}$ into the chamber.
Each rat's tail extended through a hole in the rear of each apparatus and was taped to a Plexiglas rod. Unscrambled shocks were delivered to the tails of some of the rats through fixed electrodes from a constant-current Lafayette 82400 shock source. Each wheelturn box was housed in a sound-attenuating chamber equipped with a white-noise speaker, a houselight, and a ventilating fan. All treatment contingencies were electronically controlled, and the wheelturn latencies made during escape training were automatically recorded by an electric printout timer.

The conditioned-defensive-burying boxes and the shuttlebox apparatus used to obtain stress-odor bedding from donor rats were identical to those used in Experiment 1.

Procedure. All subjects were handled and habituated to the defensive-burying chamber using a procedure similar to that of Experiment 1 . On Days 1 and 2, they were habituated to the chamber in groups of 3 for $30 \mathrm{~min}$, and on Days 3 and 4 they were habituated individually for $30 \mathrm{~min}$.

On Day 5, the rats were assigned randomly to one of three conditions: escapable shock (E), yoked-inescapable shock (Y), or restrained/no shock $(R)$. Each subject was tested individually in a wheel-turn box. Group $E$ subjects received 80 trials of escape training on a random-time schedule with a mean interval of $60 \mathrm{sec}$ and a range of 30-120 sec. Shock terminated when the rat completed a one-quarter turn of the wheel beyond $.8 \mathrm{sec}$ following the onset of shock. Wheel turns during the first $.8 \mathrm{sec}$ of shock were considered to be unlearned shock-elicited responses, which would not function as an effective coping response (see Maier \& Jackson, 1977, for a more complete description of the rationale for this procedure). All of these short-latency responses were programmed to have no consequence. Shock presentations, delivered via tail electrodes, terminated after $30 \mathrm{sec}$ if an escape response had not occurred. The shock intensity for all rats in Groups $E$ and $Y$ was begun at $.8 \mathrm{~mA}$ and then increased to $1.0 \mathrm{~mA}$ on Trial 20 , to $1.3 \mathrm{~mA}$ on Trial 40 , and to $1.6 \mathrm{~mA}$ on Trial 60 . This was done because previous studies (e.g., Williams, 1982, 1984) had revealed a deterioration of sustained wheel-turn escape performance if the intensity of the shock was not increased in this manner over the course of the session. The yoked design ensured that the subjects in Group $Y$ received the same number, duration, and intensity of shocks as did their Group E partners. Shock began simultaneously for both subjects and terminated whenever the partner rat in Group $\mathrm{E}$ made the appropriate wheel-tum response. The control subjects in Group $R$ were restrained in the same wheel-turn boxes for a $90-$ min period, but received no shock.

The procedures used to obtain stress-odor bedding from donor conspecifics and to assess burying and freezing were the same as those used in Experiment 1 .

\section{Results and Discussion}

All of the rats in Group E learned to escape from shock by turning the wheel. The mean latency to respond during the final block of 10 trials was $2.42 \mathrm{sec}$, which was significantly shorter than the mean latency of $4.98 \mathrm{sec}$ during the first block of 10 trials $[t(7)=3.75, p<.01]$. By the final block of 10 trials, none of the Group $Y$ rats turned the wheel.

Figure 3 presents the mean duration of burying, height of piles, and duration of freezing for Groups E, Y, and $R$. A one-way analysis of variance indicated that the three groups differed significantly in duration of burying behavior $[F(2,21)=6.73, p<.01]$. Newman-Keuls post hoc comparisons showed that Group Y differed significantly $(p<.1)$ from the other two groups. A similar pattern of results was found for the three groups in terms of height of the bedding piles that were measured at the 
end of the test session. Again, a one-way analysis of variance revealed that the groups differed significantly $[F(2,21)=12.29, p<.01]$. A Newman-Keuls test indicated that Group Y differed significantly from both Group E $(p<.05)$ and Group R $(p<.01)$, and that Group $\mathrm{E}$ differed significantly from Group $\mathrm{R}(p<.05)$. Together, these two measures clearly demonstrate that defensive burying was suppressed significantly more by prior exposure to inescapable-yoked shock than by escapable shock. Spearman correlations indicated that these two measures of defensive burying were positively related within each of the groups. Significant $r$ values were found for Group $\mathrm{E}[r(6)=.68, p<.05]$ and Group $\mathrm{R}[r(6)$ $=.98, p<.01]$, with Group $Y[r(6)=.54]$ approaching a significant value at the .05 level.

The durations of freezing during tests of burying for the three groups are also shown in Figure 3. The findings for freezing behavior are opposite those for burying, with Group Y showing more defensive freezing. This observation was confirmed statistically by a one-way analysis of variance showing a significant effect between groups $[F(2,21)=10.71, p<.01]$, and by post hoc tests revealing that Group Y differed significantly $(p s<.01)$ from the remaining two groups, which did not differ from each other. As was the case in Experiment 1, within-group Spearman correlations for the freezing scores versus the duration-of-burying and height-of-piles scores were all significantly $(p<.01)$ negative, with $r$ values ranging from -.83 to -.89 . Finally, the ratings of the unconditioned reactions to prod shock revealed no significant differences between the groups, suggesting that the behavioral differences noted previously were not the result of differential pain sensitivity.
The results of this experiment are the first in the literature to verify the notion that shock controllability versus uncontrollability is an important factor in determining the extent to which rats show burying and freezing during later tests of conditioned defensive burying. Although it must be assumed that all of the rats in this study showed some suppression in burying and an increase in freezing as unconditioned reactions to the presence of conspecific stress odors during testing, this factor obviously did not preclude the possibility of finding significant differences among the three groups. In fact, the results of this experiment, in conjunction with the synergistic effect of preshock and stress odors seen in Experiment 1, suggest that stress odors may have functioned as powerful conditioned fear stimuli. The degree of contextual fear elicited by such odors appears to have been far greater in the case of inescapable than escapable shock. Finally, this fear was found to produce opposite effects in two dissimilar types of defensive behaviors (i.e., less burying and more freezing) when subjects were reexposed to the stress odors in the test environment.

\section{GENERAL DISCUSSION}

The conditioned defensive burying paradigm served as a very useful and sensitive technique for measuring the effects of both conditioned and unconditioned fear stimuli by means of an active (i.e., burying) as well as a passive (i.e., freezing) form of defensive responding. Consistent with previously reported studies on the behavioral effects produced by conspecific stress odors (e.g., Dua \& Dobson, 1974; Mackay-Sim \& Laing, 1981), the presence of such odors in the test bedding was found to interfere sig-
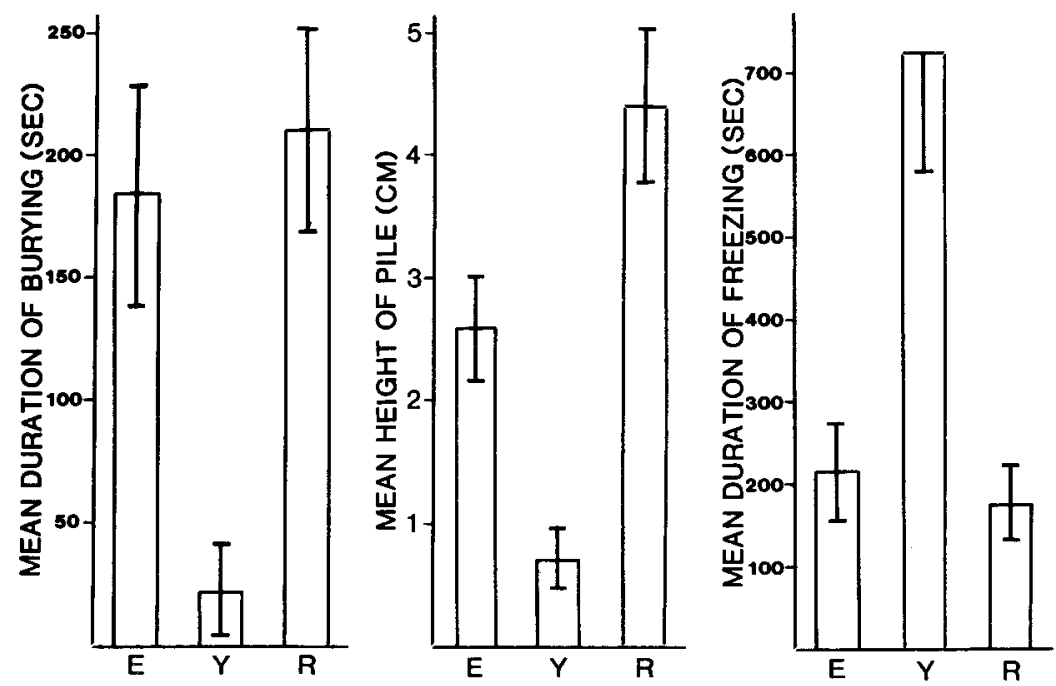

Figure 3. Mean duration of burying (left panel), height of piles (middle panel), and duration of freezing (right panel) for groups of subjects given escapable shock (Group E) or yoked inescapable shock (Group Y) or restrained without shock (Group R) during a session of conditioned defensive burying given $24 \mathrm{~h}$ later with conspecific stress odors present in the bedding material. 
nificantly with burying and to enhance freezing. The same pattern of responses was observed when subjects had been exposed to a series of inescapable shocks $24 \mathrm{~h}$ before tests of conditioned burying and freezing. Furthermore, the combination of preshock and later testing with the stress odors in the bedding resulted in the virtual elimination of burying and a striking increase in freezing. Finally, Experiment 2 demonstrated that the disruption in burying and the increment in freezing for rats tested in the presence of stress odors occurred only for subjects given prior experience with inescapable, as opposed to escapable, shock. Therefore, stress controllability was clearly a major factor in modifying these responses, and this research depicts another instance of learned helplessness, using a novel paradigm that permits the simultaneous examination of two species-typical defensive behaviors.

Maier and his colleagues (see Maier et al., 1983, for a review) have shown that exposure to inescapable shock, using preshock and triadic procedures similar to those employed in the present experiments, produces an opioidmediated analgesia reaction during tail-flick tests $24 \mathrm{~h}$ after the stress session. However, these researchers have repeatedly noted that a long-term analgesic reaction requires that the subjects be given priming shocks immediately before the nociceptive test session. When these priming shocks are not given, there appears to be no evidence of an antinociceptive reaction, even though subjects may have had a session of inescapable shocks on the previous day. Because priming shocks were not given in the present study and no significant differences in the unconditioned reactions to prod shock were found among the groups, it is difficult to attribute the reduction in burying to an attenuation of the pain produced by the prod shock. Finally, the possibility that the prod did not become a conditioned stimulus as a result of an associative-blocking effect produced by the contextual odors does not seem to account for these findings, because the rats spent most of their time freezing in one of the two corners of the chamber farthest from the prod, indicating that it had become a conditioned fear stimulus.

The SCFD theory (Williams \& Lierle, 1986) considers all examples of learned helplessness to be the result of the classical conditioning of contextual fear, which is assumed to be greater for organisms that have experienced an uncontrollable, rather than controllable, stressor. A number of earlier studies provide support for this assumption (e.g., Desiderato \& Newman, 1971; F. Osborne, Mattingly, Redmond, \& J. Osborne, 1975). Mineka et al. (1984, Experiments 1 and 2) reported that the defensive response of freezing was not only a sensitive index of fear, but that signaled escapable shock produced less freezing than did signaled inescapable shock when subjects were subsequently tested for freezing to the CS in a situation that differed from the one in which they were conditioned. The mechanism responsible for this differential fear conditioning was attributed to the "safety-signal" or fearreducing effects involved in the feedback from making the escape response. Support for this assumption was found in later experiments that indicated that yoked rats receiving a feedback signal at the time their escape partners made a response showed a lower level of fear, comparable to that found in an escape group and significantly less than that of a yoked group of subjects that did not have the feedback stimulus (Mineka et al., 1984, Experiments 3 and 4). In a similar vein, Overmier et al. (1985) more recently demonstrated that providing rats with safety signals during Pavlovian conditioning resulted in proactive protection against restraint ulceration, similar to that provided by escape responses.

As mentioned, prior exposure to shock enhanced freezing and interfered with defensive burying when stress odors were not present during prod testing. These reactions may have been the result of some type of nonassociative transfer of fear (e.g., sensitization due to handling). In addition, the increased freezing and decreased burying found for nonshocked rats tested with stress odors was probably the result of the unconditioned fear elicited by these odors (e.g., Dua \& Dobson, 1974). However, the synergistic influence of the combination of preshock and the presence of stress odors can best be explained in terms of the SCFD theory. According to this interpretation, the stress odors from conspecifics should have become conditioned fear stimuli during the subject's exposure to inescapable, but not escapable, shock. Thus, when similar stress odors were present during subsequent testing, these odors are assumed to have elicited an unconditioned as well as a conditioned fear reaction. More research is obviously needed to determine the exact stimulus-control properties of these stress odors and the precise response interactions involved in this type of potentiation.

An important question concerning the present findings is why freezing, as opposed to burying, occurred as a result of prior exposure to shock and/or the presence of conspecific stress odors. The discriminative stimulus that controlled burying behavior in these studies was obviously the localized CS prod that was paired with shock. In contrast, freezing is assumed to have been instigated and maintained by the fear odors that were present throughout the bedding of the test chamber. The fact that enhanced freezing occurred in the presence of these odors is consistent with numerous studies showing that freezing is the dominant conditioned response to static, inescapable environmental or contextual cues paired with aversive stimuli (e.g., D. C. Blanchard \& R. J. Blanchard, 1969; Fanselow \& Baackes, 1982). The stimulus control and conditioned fear response associated with the stress odors are assumed to be greater than those associated with the prod for several reasons. First, such odors were undoubtedly very salient, because they are innately recognized by rats as fear stimuli (Fanselow, 1985). Second, as a nonlocalized source of fear throughout the bedding manipulandum, these odors should suppress burying and produce a nondirectional form of defense (i.e., freezing). Finally, it is assumed that $\mathbf{8 0}$ trials of prior inescapable shock, in contrast to the single and very brief prod shock, would enable the stress odors to elicit a much stronger condi- 
tioned fear reaction for preshocked subjects. Thus, the predominance of freezing by some groups in these experiments suggests that there were differentially conditioned, competing sources of stimulus control in the test situation. Although this interpretation does not preclude the possibility of a hierarchical organization of speciesspecific defense reactions (Bolles, 1970), such a concept seems somewhat superfluous in explaining these findings.

Even though prod burying functions as a defensive behavior in terms of removing a potentially dangerous stimulus, I question whether burying should be classified as a form of "defense"' in terms of an ethological perspective. For example, there are no reports of rats' burying as a defensive response to a dominant conspecific or a threatening predator. Furthermore, the results of the present experiments show that fear suppresses, rather than activates, burying. Finally, contrary to Pinel (e.g., Pinel \& Treit, 1978), these data are consistent with the findings of Moser and Tait (1983) and Modaresi (1983) in that they suggest that burying seems to occur only after freezing to the prod shock has completely ceased. One interpretation of this phenomenon is that the rats are attempting to escape from the prod by burrowing. Peacock and Wong (1982) found that burrowing, which is known to be a highly effective defensive response in the rat, was performed by more rats than was burying during tests with prod shock. Another possibility is that burying in this situation may actually be a nest-maintenance response. Although this may seem to be an inappropriate postshock behavior, it may be an example of a displacement activity in response to the frustration produced by the continued presence of the prod; it could also be a schedule-induced, adjunctive response that occurs in the absence of a reinforcer (see Fanselow, Sigmundi, \& Williams, 1987, for further discussion of this issue).

In conclusion, the complex alterations of learned and unlearned species-typical behaviors as a result of fear induced by stress uncontrollability are undoubtedly mediated by a variety of associative, perceptual, ethological, and neurophysiological processes. The present findings clearly indicate that the defensive-burying paradigm is an excellent technique for assessing the degree of fear elicited by contextual cues such as stress odors. At the same time, this research suggests that the classification of burying as a species-specific defense reaction requires systematic reexamination.

\section{REFERENCES}

Anisman, H. SUISSA, A., \&KLAR, L. S. (1980). Escape deficits induced by uncontrollable stress: Antagonism by norepinephrine and dopamine agonists. Behavioral \& Neural Biology, 28, 34-47.

Blanchard, D. C., \& Blanchard, R. J. (1969). Crouching as an index of fear. Journal of Comparative \& Physiological Psychology, 67, 370-375.

BlanChaRd, D. C., \& Blanchard, R. J. (1984). Inadequacy of painaggression hypothesis revealed in naturalistic settings. Aggressive Behavior, 10, 33-46.

Blanchard, R. J., Flannelly, K. J., \& Blanchard, D. C. (1986).
Defensive behaviors of laboratory and wild Rattus norvegicus. Journal of Comparative Psychology, 100, 101-107.

Blanchard, R. J., Fukunaga, K. K., \& Blanchard, D. C. (1976). Environmental control of defensive reactions to a cat. Bulletin of the Psychonomic Society, 8, 179-181.

Bolles, R. C. (1970). Species-specific defensive reactions and avoidance learning. Psychological Review, 71, 32-48.

Brown, R. J. (1979). Mammalian social odors: A critical review. In J. S. Rosenblatt, R. A. Hinde, L. Beer, \& M. Busnel (Eds.), $A d-$ vances in the study of behavior (Vol. 10, pp. 103-160). New York: Academic Press.

Bruto, V., ANISMAN, H. (1983). Alteration of exploratory patterns induced by uncontrollable shock. Behavioral \& Neural Biology, 37, 302-316.

Desiderato, O., Newman, A. (1971). Conditioned suppression produced in rats by tones paired with escapable or inescapable shock. Journal of Comparative \& Physiological Psychology, 77, 427-431.

Drugan, R. C., \& MaIER, S. F. (1982). The nature of the activity deficit produced by inescapable shock. Animal Learning \& Behavior, 10, 401-406.

DuA, J. K., Dobson, M. J. (1974). Role of olfactory cues in acquisition and extinction of avoidance. Journal of Experimental Psychology, 103, 461-465.

FANSELOW, M. S. (1985). Odors released by stressed rats produce opioid analgesia in unstressed rats. Behavioral Neuroscience, 99, 589-592.

FANSELOW, M. S., B BAACKES, M. P. (1982). Conditioned fear-induced opiate analgesia on the formalin test: Evidence for two aversive motivational systems. Learning \& Motivation, 13, 200-221.

FANSELOW, M. S., \& LeSTER, L. S. (in press). A functional behavioristic approach to aversively motivated behavior: Predatory imminence as a determinant of the topography of defensive behavior. In R. C. Bolles \& M. D. Beecher (Eds.), Evolution and learning. Hillsdale, NJ: Erlbaum.

Fanselow, M. S., Sigmundi, R. A., \& Williams, J. L. (1987). Response selection and hierarchical organization of species-specific defense reactions: The relationship between freezing, flight, and defensive burying. Psychological Record, 37, 381-386.

Gray, D. S., Terleckı, L. J., Treit, D., \& Pinel, J. P. J. (1981). Effect of septal lesions on conditioned defensive burying. Physiology \& Behavior, 27, 1051-1056.

Mackay-Sim, A., Laing, D. G. (1981). The sources of odors from stressed rats. Physiology \& Behavior, 27, 511-513.

Maier, S. F., Drugan, R., Grau, J. W., Hyson, R., Maclennan, A. J., Moye, T., Madden, J., \& Barchas, J. D. (1983). Leamed helplessness, pain inhibition and the endogenous opiates. In M. D. Zeiler \& P. Harzem (Eds.), Advances in animal behavior (Vol. 3, pp. 275-323). New York: Wiley.

MAIER, S. F., JACKSON, R. L. (1977). The nature of the initial coping response and the learned helplessness effect. Animal Learning \& Behavior, 5, 407-414.

MineKA, S., CoOK, M., \& Miller, S. (1984). Fear conditioned with escapable and inescapable shock: Effects of a feedback stimulus. Journal of Experimental Psychology: Animal Behavior Processes, 10, 307-323.

MinoR, J. R., LoLordo, V. M. (1984). Escape deficits following inescapable shock: The role of contextual odor. Journal of Experimental Psychology: Animal Behavior Processes, 10, 168-181.

MODARESI, H. A. (1982). Defensive behavior of the rat in a shock-prod situation: Effects of the subject's location preference. Animal Leaming \& Behavior, 10, 97-102.

Moser, C. G., \& TAIT, R. W. (1983). Environmental control of multiple defensive responses in a conditioned burying paradigm. Journal of Comparative Psychology, 17, 338-352.

Oberdieck, F. G., \& Cheney, C. D. (1982). The effect of context change on conditioned defensive burying in rats. Bulletin of the Psychonomic Society, 19, 295-297.

Osborne, F., Mattingly, B., Redmond, W., \& Osborne, J. (1975). Factors affecting the measurement of classically conditioned fear in rats following exposure to escapable versus inescapable signalled 
shock. Journal of Experimental Psychology: Animal Behavior Processes, 1, 364-373.

Overmier, J. B., Murison, R., Skoglund, E. J., \& Ursin, H. (1985) Safety signals can mimic responses in reducing the ulcerogenic effects of prior shock. Physiological Psychology, 13, 243-247.

Peacock, E. L., \& Wong, P. T. P. (1982). Defensive burying in the rat: A behavioral field analysis. Animal Learning \& Behavior, 10, 103-107.

Pinel, J. P. J., \& Treit, D. (1978). Burying as a defensive response in rats. Journal of Comparative \& Physiological Psychology, 92, 708-712.

Pinel, J. P. J., \& Treit, D. (1979). Conditioned defensive burying in rats: Availability of burying materials. Animal Learning \& Behavior, 7, 392-396.

Pinel, J. P. J., \& Treit, D. (1981). The conditioned defensive burying paradigm and behavioral neuroscience. In T. E. Robinson (Ed.), Behavioral contributions to brain research (pp. 212-234). Oxford, England: Oxford University Press.

Pinel, J. P. J., \& Wilkie, D. M. (1983). Conditioned defensive burying: A biological and cognitive approach to avoidance learning. In R. L. Mellgren (Ed.), Animal cognition and behavior (pp. 285-318). Amsterdam: North-Holland.

RoselLiNI, R. A. (1978). Inescapable shock interferes with the acquisition of an appetitive operant. Animal Learning \& Behavior, 6, 155-159.
Terlecki, L. J., Pinel, J. P. J., \& Treit, D. (1979). Conditioned and unconditioned defensive burying in the rat. Learning \& Motivation, $10,337-350$.

VAlENTA, J. G., \& RigbY, M. K. (1968). Discrimination of the odor of stressed rats. Science, 161, 599-600.

Weiss, J., Goodman, P., Losito, B., Corrigan, S., Charry, J., \& BAILEY, W. (1981). Behavioral depression produced by an uncontrollable stressor: Relationship to norepinephrine, dopamine, and serotonin levels in various regions of rat brain. Brain Research Review, 3, 167-205.

WILLIAMS, J. L. (1982). Influence of shock controllability by dominant rats on subsequent attack and defensive behaviors toward colony intruders. Animal Leaming \& Behavior, 10, 305-313.

WiLliams, J. L. (1984). Influence of postpartum shock controllability on subsequent maternal behavior in rats. Animal Learning \& Behavior, 12, 209-216.

Williams, J. L., \& LiERLE, D. M. (1986). Effects of stress controllability, immunization, and therapy on the subsequent defeat of colony intruders. Animal Learning \& Behavior, 14, 305-314.

(Manuscript received August 7, 1986; revision accepted for publication February 9, 1987.) 